\title{
GLOBALIZAÇÃO E IDENTIDADE NO CONTEXTO DA ESCOLA E DO CURRÍCULO
}

\author{
JOSÉ AUGUSTO PACHECO \\ jpacheco@iep.uminho.pt \\ NANCY PEREIRA \\ nancypereira79@portugalmail.pt \\ Instituto de Psicologia e Educação da Universidade do Minho
}

\begin{abstract}
RESUMO
O artigo pretende discutir a globalização e a identidade no contexto da escola e do currículo, como dois espaços posicionais que configuram as políticas de ensino, concretamente ao nível da organização escolar. Defendemos que a globalização contribui de modo efectivo, contrariamente ao que a construção das identidades escolares pressupõe, não só para o reforço da homogeneização escolar, incluindo as práticas curriculares, como também para o reforço da noção de currículo como facto. Os resultados que se apresentam dizem respeito às práticas de elaboração de projectos educativos (político-pedagógicos) configurando a existência de projectos que são trabalhados escolarmente pelos professores numa lógica normativa e num ritual de cumprimento de macrodecisões, mesmo que a sua justificação seja feita na base da autonomia das escolas e de identidades curriculares locais.

GLOBALIZAÇÃO - IDENTIDADE - ESCOLAS - CURRICULOS
\end{abstract}

\section{ABSTRACT}

GLOBALIZATION AND IDENTITY IN THE CONTEXT OF SCHOOL AND CURRICULUM. This article intends to discuss from the point of view of school and curriculum, globalization and identity as two position spaces that concretely configure the education politics at the level of the school organization. We defend that the globalization contributes in an effective way not only for the reinforcement of the school homogenization, including the curriculum practices, but also for the reinforcement of the curriculum concept as a fact. This view is, consequently, against what the construction of the school identity presupposes. The results presented here are concerned with the practices of elaboration of educational projects (political-pedagogical ones). It was found that the teachers develop some of these projects according to a normative logic and following a ritual whose aim is to implement macrodecision. This is done even in name of schools' autonomy and/or the constitution of the identity of local curriculum.

GLOBALIZATION - IDENTITY - SCHOOL-CURRICULUM 
Globalização e identidade são dois conceitos que, analisados no contexto das políticas educacionais e curriculares, não podem ser entendidos como se fossem dois extremos opostos e excludentes, mas como espaços posicionais e relacionais que são, tal como preconiza Hall (2003, p.45-46) para a abordagem do global e local: "Hoje em dia, o meramente local e o global estão atados um ao outro, não porque este último seja o manejo local dos efeitos essencialmente globais, mas porque cada um é a condição de existência do outro".

Falar de globalização e identidade nos espaços escolares e nos terrenos da organização curricular, isto é, na forma e conteúdo da escolarização, implica debater as estruturas mundiais hegemónicas nos mais diversos quadrantes, desde o económico e financeiro até o político e cultural. As escolas e o currículo fazem parte destas estruturas de homogeneização pela especificidade das suas funções de educação e formação, já que currículo só existe a partir do momento em que se elabora um projecto de vinculação social a organizações formais e/ou informais. Estas constroem as suas identidades em diversas lógicas, das quais destacaremos as de legitimação, de projecto e de resistência, no seguimento do conceito de identidade que é explorado por Castells (2000).

Assim, toda e qualquer discussão escolar e curricular relativa a globalização e identidade necessita de incorporar a questão do conhecimento, quer como instrumento de homogeneização e diversificação cultural, quer como recurso de formação dos sujeitos. Neste texto, defendemos que a globalização, enquanto estratégia de homogeneização cultural, que tem como ideologia de base o neoliberalismo, traz uma linguagem de uniformização para a escola que não lhe é totalmente estranha, contribuindo para a retylerizaçãol das práticas curriculares, sobretudo com o reforço da lógica dos conteúdos, competências e avaliação. Defendemos também que as identidades de actores educativos e de organizações escolares - dentro de um léxico comum que integra, entre outras palavras, "autonomia", "descentralização", "projecto" e "comunidade" - existem mais no plano dos discursos políticos burocráticos do que nas práticas políticas de professores e alunos.

I. Retorno a Tyler (back to Tyler), aceitando-se que o currículo é um plano, um dispositivo normativo definido pela administração, embora possa ser gerido pelos professores, desde que essa gestão seja controlada pelo currículo nacional e pela avaliação estandardizada. 
Globalização e identidade...

Torna-se necessário, deste modo, reflectir sobre o que se pretende fazer da escola e dos seus projectos de formação, passando-se de uma linguagem reactiva e de denúncia dos malefícios da globalização para uma intervenção educacional. Isto comporta a politização do currículo e dos actores que o configuram na prática, uma vez que a globalização traduz-se numa "política de despolitização" (Bourdieu, 200 I, p.60), que desavergonhadamente bebe no léxico da liberdade e também, para Paulo Freire (1996), no da ética².

Reiteramos o propósito de analisar o que a globalização faz no sentido de reforçar a concepção macropolítica do currículo e de que modo as escolas, enquanto espaços de produção de identidades, funcionam como dispositivos de homogeneização. Nosso argumento é que as escolas são organizações receptivas à globalização, pois há mais traços que as unificam do que as distinguem, e que esta última origina um pensar e um fazer curriculares centrados na linguagem tyleriana, sobretudo se for colocada no centro do debate a questão do conhecimento.

\section{GLOBALIZAÇÃO}

O debate sobre a educação é uma variante constante de cada sociedade a partir do momento em que se coloca esta interrogação muito simples: "Para que serve a escola?" (Kress, 2003, p.20). Mais acutilante ainda quando é certo que se deseja que a escola continue, pois ainda não fomos capazes de a substituir por outra melhor ${ }^{3}$, e que a lógica da sua fundação reforça-se à medida que os problemas sociais colocam novos desafios e reeditam as incertezas. Neste sentido, há um permanente questionamento do papel da escola e uma

2. Escreve Paulo Freire que "o discurso da globalização que fala da ética esconde, porém, que a sua é a ética do mercado e não a ética universal do ser humano, pela qual devemos lutar bravamente se optamos, na verdade, por um mundo de gente" (1996, p. I27).

3. Para António Nóvoa, "historicamente, a escola falhou muitas promessas, mas também cumpriu alguns desígnios. Não vale a pena travar este debate sob o signo da acusação ou do maniqueísmo (...) o debate não pode ficar fechado nos interesses das famílias ou dos alunos, nas necessidades da economia ou da sociedade, nas posições do Estado ou das comunidades locais, nos pontos de vista dos professores ou dos especialistas. Todos são precisos para travar o debate sobre a escola e para encontrar rumos novos para uma instituição que, apesar de tudo, ainda não fomos capazes de substituir por outra" (Nóvoa, 2004). 
discussão sobre a sua funcionalidade em termos de resultados de aprendizagem. Esta discussão sobre o papel da escola ganha ainda mais vivacidade em tempos de incerteza, tal como podem ser considerados os que se referem às últimas décadas do século $X X$ e às primeiras do século $X X \mid$. No entendimento de Arrighi e Silver

...a globalização do sistema mundial moderno ocorreu, portanto, através de uma série de rupturas dos padrões estabelecidos de governo, acumulação e coesão social, no decurso das quais uma ordem hegemônica estabelecida entrou em decadência, enquanto uma nova ordem emergiu intersticialmente e, com o correr do tempo, tornou-se hegemônica. $\bigcirc$ intervalo entre a decadência do velho e a formação e estabelecimento do novo, observou John Calhoun, constitui um período de transição que, necessariamente, tem que ser sempre de incerteza, confusão, erro e fanatismo desvairado e feroz. (200I, p.28I)

Em tempos de mudanças significativas, e não restam dúvidas que a revolução tecnológica, ligada à informática, será um marco miliário na configuração dos períodos da história, desde a revolução neolítica até à revolução industrial, a globalização traz novos argumentos para o debate em torno da escola. Tem a pretensão de instaurar uma "pedagogia mundial" (Kress, 2003), na reedição do pensamento de Comenio, mas agora visando ensinar a todos, na base de uma cultura mundial, competências de tecnologias de informação e comunicação. Daí que "o currículo tem-se tornado mais global", no dizer de Willinsky (2003, p.99).

Contudo, este desígnio global que busca a homogeneização dos espaços escolares tem como contraponto a questão da diversidade e identidade, que acentua a dicotomia global/local (Teixeira, 200 I) e valoriza as micropolíticas e as políticas de descentralização (Pacheco, 2005), mediante a outorga aos Estados $^{4}$, às escolas e aos professores de uma pretensa autonomia.

4. Em princípio é contraditória a junção do global com o local (entendido aqui como espaço territorial de um Estado, das suas escolas e dos seus professores: "A globalização com certeza apresenta novos problemas para os Estados, mas igualmente fortalece o princípio cultural mundial de que os Estados-nação são os principais agentes encarregados de identificar e gerenciar esses problemas em nome de suas sociedades" (Meyer et al., apud Ladwig, 2003, p.270). 
Globalização e identidade...

Se estamos num momento de viragem, Kress (2003) identifica os seguintes factores que marcam o presente escolar: mudança do poder do Estado para o mercado; mudança do cidadão para o consumidor; mudança da sociedade monocultural para a sociedade multicultural; mudança da indústria secundária e terciária para a indústria da informação/conhecimento; mudança nas formas de autoridade do saber (do texto para a imagem).

Esses factores estão na base da construção da sociedade do conhecimento (Touraine, 1984; Hargreaves, 2004). Por isso, a escola, cuja razão de ser é o conhecimento nas suas mais diversas formas de abordagem, passa a ser vista como um dos pilares fundamentais dessa sociedade, e reconhecida como "uma instituição cultural mundial" (Ladwig, 2003, p.266). Que os alunos dominem o conhecimento escolar é uma prioridade básica para os especialistas das macropolíticas. É imprescindível que a escola trabalhe os saberes, que constituem o núcleo do currículo para a formação de alunos e cidadãos globalizados, assim identificados por Morin:

O conhecimento do mundo como mundo é necessidade ao mesmo tempo intelectual e vital. É o problema universal de todo cidadão do novo milênio: como ter acesso às informações sobre o mundo e como ter a possibilidade de articulálas e organizá-las? Como perceber e conceber o Contexto, o Global (a relação todo/partes), o Multidimensional, o Complexo? (200 I, p.35)

Na prática, estes saberes reduzem-se a uma perspectiva mais pragmática, com a valorização de saberes de determinados campos disciplinares, a que não é indiferente o seu valor simbólico, e de orientações essencialmente tecnicistas, incutindo-se nos alunos uma visão utilitária da escola. A este respeito interroga-se Ladwig: "Por que motivos os alunos passam a ver essa forma de conhecimento (e as habilidades e aptidões necessárias para tornar esse conhecimento público) como absolutamente valiosa e desejável?" (2003, p.283).

Globalização e identidade são duas palavras com sentidos diferentes que jamais estiveram tão próximas, sobretudo se utilizadas na definição das políticas sociais, económicas e culturais. Por mais que afectem o lado das pessoas, nas suas identidades construídas nos contextos em que se inserem, as mudanças em curso são globais. Elas actuam em dimensões cujo traço comum é a compressão do espaço e a criação de lógicas identitárias que configuram uma 
racionalidade económica, embora a globalização, acima de tudo, seja política, tecnológica e cultural (Giddens, 2000).

A globalização consiste na definição de novas identidades pessoais, profissionais, nacionais e supranacionais, impondo a uma outra escala novas regras e novos procedimentos para a resolução dos problemas colocados no âmbito da sociedade do conhecimento e do capitalismo informacional (Castells, 2000b).

Estando conectada numa rede (Castells, 2000), a globalização contribui para a definição de macropolíticas (Ball, 1997), na base das quais se encontram racionalidades técnicas e modelos de comportamento que levam à recontextualização de políticas educacionais. Aceitando-se que a globalização é uma ideologia dominante imposta e regulada pela lógica de mercado, com vista à instituição de novas identidades, é necessário analisar de que modo a macroregulação das políticas contribui para a regionalização de identidades nacionais partindo de uma vontade supranacional negociada ao nível das políticas económicas e sociais e das políticas de educação e formação. E de que modo favorece a convergência das práticas escolares ao mesmo tempo em que os discursos são legitimados pela noção de descentralização e pelo reforço da autonomia das escolas no que diz respeito ao seu projecto educativo e aos seus projectos curriculares.

Assim, existe, de um lado, a globalização, ou mundialização, tendo como consequência a necessidade de implementar políticas que privilegiam a melhoria da qualidade da educação de modo a assegurar a formação de uma mão-deobra qualificada, susceptível de dar os trunfos numa concorrência internacional; de outro lado, a regionalização, que consiste no agrupamento de países (União Europeia, Mercosul...) e pela devolução de poderes a nível intranacional. A regionalização traduz-se igualmente pela procura da melhoria da quantidade subscrita na proposição de standards e de normas, os mais elevados possíveis para uma dada região geográfica (Hallak, 200 I). Na região geográfica da União Europeia, a globalização educacional traduz-se em registos de formação centrados na aquisição de competências, ligadas às Ciências, à Matemática, ao Inglês e às Tecnologias de Informação e Comunicação, com vista à edificação da Europa do conhecimento.

A língua é um factor preponderante na cimentação de uma cultura comum, e o Inglês transforma-se, na União Europeia, na "segunda primeira língua", como diz Habermas: 
Globalização e identidade...

No entanto - enquanto houver vontade política para isso - nada depõe a fortiori contra a possibilidade de se criar o contexto comunicacional politicamente necessário em uma Europa que cresce unida (econômica, social e administrativamente) e na qual se dispõe de uma base cultural comum e uma experiência histórica conjunta de bem-sucedida superação do nacionalismo. Na verdade, para que esse contexto de comunicação se estabeleça parece faltar apenas um desencadeamento por via jurídica constitucional. Também a exigência de uma língua comum - inglês como second first language - poderia deixar de representar um empecilho intransponível, haja vista a situação atual da educação escolar formal nos países europeus. Identidade européia não pode significar senão unidade na pluralidade nacional. (Habermas, 2002, p. I 84)

Para as Tecnologias, segundo Ilona Kovács (2002, p. I 49), a informação torna-se uma "variável central da economia, suplantando o trabalho e o capital como fonte de valor acrescentado", e o ensino/formação é um dos principais meios de adaptação, "constituindo uma fonte importante de alta performance, ou seja, da manutenção ou amento da competitividade".

Mesmo que se fale do local, de identidade, descentralização e autonomia, a questão da uniformização das escolas continua a ser uma realidade, e provavelmente o Estado persistirá "na uniformização de práticas, valores, conhecimentos e disposições" (Kress, 2003, p. 120) e no cumprimento de uma agenda educacional globalizada.

A globalização traz o debate sobre o papel do Estado, discutindo-se o seu protagonismo ou redução. Para Arrighi e Silver (200 I, p. I6), "a globalização está relacionada com a emergência de organismos transnacionais que não devem lealdade a país algum nem se sentem em casa de nenhum deles". A partir de um estudo sobre a hegemonia de longos períodos (de 1500 a 2025) de expansão competitiva, que resulta em uma concentração particular de poder económico e político, esses autores têm a seguinte proposição:

Ao contrário da expansão financeira global, a proliferação do número e variedade de organizações e comunidades empresariais transnacionais é uma característica nova e provavelmente irreversível da atual crise hegemônica. Foi um fator fundamental na desintegração da ordem econômica norte-americana, e podemos esperar que continue a moldar a mudança sistêmica em andamento, atra- 
vés de uma perda generalizada mas não universal do poder dos Estados. (Arrighi, Silver, 200I, p.287)

Discuta-se ou não o lugar do Estado na globalização, há a registar a desnacionalização da produção económica, como escreve Habermas:

Nos últimos tempos, todos os países industrializados são afetados pela circunstância de que as estratégias de investimento de um número cada vez maior de empresas orientam-se pelos mercados financeiros e de trabalho, organizados hoje em rede mundial. (2002, p.139)

Donde, chegando o Estado nacional ao seu fim, num processo de supra-assunção, o lugar é ocupado pela empresa transnacional, tendo como horizonte a "sociedade global descentrada, que se decompõe em uma quantidade desordenada de sistemas funcionais que se reproduzem e se orientam a si mesmos" (p. |43).

No caso da União Europeia, os Estados-membros têm hoje em dia uma política comum, dentro daquilo a que Santos (200l, p.93) chama "globalização de baixa intensidade" ${ }^{5}$ e Teodoro (2003, p.56) designa por "agenda globalmente estruturada", sendo previsível que os seus efeitos nas políticas nacionais tendam para a homogeneidade e uniformização em detrimento da diversidade e multiplicidade ${ }^{6}$.

Mais do que definir globalização, é necessário observar os seus efeitos nas práticas escolares e curriculares e estudar de que modo influencia o pensamento curricular. Com efeito, interessa-nos, tal como propõe Gough (2003, p. I 48), conhecer "o modo como a globalização trabalha, e o que faz, mas não o que é", e analisar o sentido das práticas curriculares de professores e outros actores sociais.

5. "A globalização de baixa intensidade tende a dominar em situações em que as trocas são menos desiguais, ou seja, em que as diferenças de poder (...) são pequenas" (Santos, 200 I , p.93).

6. António Teodoro (2003, p.56), citando Roger Dale, afirma que os efeitos da globalização nas políticas nacionais apresentam-se mais diversos e múltiplos do que homogéneos e uniformes. Discordamos desta posição no que diz respeito às políticas de conhecimento que os Estados formulam nos seus processos de decisão educacional. 
Globalização e identidade...

Tais efeitos são reconhecidos tanto na estruturação da forma quanto do conteúdo do currículo, ou seja, na formatação dos ciclos de formação do ensino superior, de que o processo de Bolonha é um indicador fiável, e na definição de "boas práticas curriculares" para os ensinos fundamental e médio. Nestes níveis de ensino, que entram, de igual modo, numa lógica de formatação ao nível de ciclos e da tendência a se fixar a escolaridade obrigatória em 12 anos, a uniformização faz-se pelo conhecimento ${ }^{7}$, método e avaliação, ligados aos alunos, e pela formação docente ${ }^{8}$.

Tendo como base políticas de conhecimento uniformes, as escolas seguem um plano curricular estruturado em disciplinas, cujos conteúdos, essencialmente daquelas que são mais estruturantes, tendem para a similaridade a nível mundial. Este sentido curricular é potencializado pela existência de estudos de avaliação internacionais, caso do Programa Internacional de Avaliação de Estudantes - Pisa -, da Organização para Cooperação e Desenvolvimento Económico - OCDE -, que contribuem para a instauração de padrões educacionais comuns, recolocando no centro do debate escolar o conhecimento.

Politicamente, como sugerem Garcia e Moreira, é importante que o conhecimento escolar esteja no centro das discussões sobre a escola ${ }^{9}$, em geral, e sobre o currículo, em particular:

A escola está sendo acusada de não conseguir ensinar, de não promover a aprendizagem do aluno, de estar formando pessoas sem os conhecimentos indispensáveis à luta por uma vida mais digna. O conhecimento é hoje cada vez mais importante para toda e qualquer criança, todo e qualquer adulto. Logo, eu vejo o processo curricular na escola girando em torno do conhecimento. Obvia-

7. Para José Gimeno (2003, p.65), "os processos de globalização afetam a educação porque incidem sobre os sujeitos, os conteúdos do currículo e as formas de aprender".

8. Para Regina Leite Garcia e Antonio Flávio Moreira (2003, p. I3), "fomos todos formados para colocar todo o mundo seguindo o rebanho, seguindo o mesmo caminho, aprendendo as mesmas coisas, no mesmo tempo".

9. Para este debate não se pode ignorar a discussão em torno da agenda pós-moderna, pois, como expressa Maria Célia Moraes (2004, p.353), "os tempos pós-modernos caracterizamse por uma pedagogia que desvaloriza o conhecimento escolar e uma epistemologia que desvaloriza o conhecimento teórico/científico/acadêmico". 
mente não é qualquer conhecimento, desprovido de qualquer sentido, mas um conhecimento que, depois de uma série de perguntas que se façam e de respostas que se dêem, e com base em um posicionamento claro e consciente, tenhamos considerado importante de estar sendo trabalho por alunos e professores. (2003, p.25)

Não se pode ignorar a questão dos padrões educacionais nas escolas, pois há saberes básicos para o desempenho de papéis sociais que os alunos necessitam de adquirir, dentro daquilo que pode ser chamado de literacias estruturantes. Este conceito liga-se à questão da padronização cultural que a escola institui na sua função de educação geral. Digamos que a padronização cultural é impositiva e também necessária. Por exemplo, em termos sociolinguísticos, para Bortoni-Ricardo

...os alunos que chegam à escola falando "nós cheguemu", "abrido" e "ele drome", por exemplo, têm que ser respeitados e valorizadas as suas peculiaridades lingüístico-culturais, mas têm o direito inalienável de aprender as variantes de prestígio dessas expressões. Não se lhes pode negar esse conhecimento, sob pena de se fecharem para eles as portas, já estreitas, da ascensão social. $\bigcirc$ caminho para uma democracia é a distribuição justa de bens culturais, entre os quais a língua é o mais importante. (2005, p. 12)

É fundamental também que se discuta a razão de ser destes padrões e a sua contribuição para a qualidade dos processos de aprendizagem ${ }^{10}$, sem ignorar os modelos de racionalidades técnicas que os justificam. É esta lógica de conteúdos que define as práticas curriculares das escolas globalizadas, originan-

10. John Willinsky (2003, p. 99) observa a existência dos padrões educacionais do seguinte modo: "Se é nosso objetivo elevar os padrões para uma quantidade maior de estudantes, devemos refletir também sobre o que eles vão herdar. Se a proposta desses padrões elevados for melhorar a qualidade de vida, examinaremos as implicações do que os estudantes aprendem e praticam, seja em estudos sociais, tecnologias da informação ou artes, com vistas a uma participação democrática em nível local, nacional e global. Do contrário, continuar supondo que a principal meta educacional é elevar as notas dos alunos nas provas parece referendar o que fazemos nas salas de aulas, sem levar em conta o grande despreparo dos alunos". 
Globalização e identidade...

do, inclusive, a recontextualização de discursos e práticas pedagógicas no sentido da articulação da pedagogia visível e invisível de Bernstein ( 1996, p. 105), em que a segunda valoriza a "aquisição-competência" e a primeira a "transmissão-desempenho". Entretanto:

...uma pedagogia visível orientada pelo mercado é, verdadeiramente, uma forma secular nascida no contexto de uma educação eficaz em termos de custos, uma educação que, supostamente, promove habilidades e atitudes relevantes, além de tecnologia, numa era de um enorme e crônico desemprego juvenil. (Bernstein, 1996, p. 127)

Por intermédio desta agenda mundial em torno do conhecimento, a escola reforça a sua estrutura homogénea de espaço de saberes, cada vez mais perspectivados pela lógica de competências (Pacheco, 2005). Não se podendo colocar em causa a educação, tão-só a escolarização nas suas formas de a concretizar, Hallak (200 I , p.43) escreve que a globalização tem como conseqüência a aparição de sociedades abertas ao conhecimento, onde "as noções de formas e conteúdos apropriados de escolarização são largamente partilhados por um número crescente de países através de agências internacionais de cooperação em educação e de troca de experiências em matéria política".

Se a globalização funciona hoje em dia no seio das práticas escolares e curriculares, pela discussão do conhecimento, nas décadas de 1980 e 1990 integrava abordagens na base da conscientização crítica dos alunos para temáticas transnacionais, por exemplo, da formação pessoal e social, do paradigma do desenvolvimento, dos estilos de vida (Gough, 2003). De um alerta inicial, a globalização passa para um conjunto de práticas que reforçam o lado mais uniformizante da escola, sendo de admitir que a escola contém, desde a sua génese e na sua estrutura de funcionamento, princípios de homogeneização. Para Sampaio (1998, p.248), as escolas, fazendo parte do mundo das organizações de tipo burocrático, devido ao seu modo predominante de regulação e exercício de poder, têm regras e poder instituídos, onde "o currículo é normatizado por regras e documentos de responsabilidade dos órgãos centrais e dos órgãos regionais, que controlam sua operacionalização e realização nas escolas".

Deste modo, a globalização torna-se numa identidade legitimadora (Castells, 2000b) de espaços geográficos cada vez mais transnacionais e 
supranacionais, que reforçam o papel de transmissão de conhecimentos com base em critérios bem definidos, que a escola tem cumprido. Ainda que as mudanças nas práticas escolares não sejam significativas, pois também é possível argumentar que existe nas escolas uma estrutura invariante ligada ao pensamento e à acção dos professores (Pacheco, 1995), as políticas educacionais ligadas à globalização reconceptualizam o currículo do seguinte modo (Martinand, 200 I): valorização da orientação escolar e profissional não nas suas componentes psicológicas, mas na contribuição para a construção de representações muito objectivas dos conteúdos e dos contextos técnicos de trabaIho; abordagem do mundo tecnicista. $\bigcirc$ mundo artificial (matérias, instrumentos, recursos, lugares e ritmos) é apresentado como um reino maquinal, substituindo os reinos naturais (mineral, vegetal, animal); visa-se à apropriação das técnicas de informação e de comunicação; à promoção de uma pedagogia de acção.

\section{IDENTIDADE}

Em tempos marcados pela globalização, com mudanças a todos os níveis, incluindo a das mentalidades, de que modo se torna possível falar de identidade como a expressão de uma pluralidade de sentidos centrados no sujeito?

A questão central é saber que tipo de identidade está subjacente ao conceito de globalização, sendo de esperar que, de acordo com a tipologia de Hall (2003), corresponda mais ao sujeito iluminista e ao sociológico do que ao sujeito pós-moderno. Trata-se, essencialmente, de criar uma cultura de responsabilidade, identificada nos termos "qualidade", "eficiência", "eficácia", e possível somente através de "uma forte flexibilidade" (Bourdieu, 200 I, p.33) e da exaltação do individualismo na perspectiva neodarwinista. A competitividade educacional, que depende dos sujeitos, é uma condição para a qualidade dos espaços escolares, concretizando-se em sucessivas avaliações externas, conducentes à comparabilidade e à responsabilização dos sujeitos pelos fracassos.

Contrariamente às políticas de fragmentação do sujeito, presentes nas denominadas abordagens pós-modernas e pós-estruturalistas, as identidades escolares correspondem, na análise das políticas educacionais e curriculares, a políticas de descentralização. Estas têm como objectivo a recentralização das

práticas, mesmo que a uniformização advenha de mudanças realizadas sob o 
Globalização e identidade...

signo da "autonomia", do "projecto político-pedagógico", do "projecto educativo", do "projecto curricular", da "participação", da "comunidade", do "território educativo".

Neste sentido, argumentamos que a globalização faz prevalecer o lado mais normativo da política do Estado e das suas formas de poder, observando-se que as políticas curriculares são descentralizadas ao nível dos discursos e recentralizadas ao nível das práticas. Se as formas de micropoder foucaultianas, no sentido do reconhecimento do poder, que é difuso e que não tem a sua origem no topo, constituem o lado subterrâneo das escolas em muitos aspectos da sua organização e das suas decisões informais, as macrodecisões, situadas no Estado e nos organismos globalizados, regulam o lado mais substantivo do currículo, isto é, o modo como está organizado (forma), quais os conhecimentos ensinados (conteúdos) e como deve ser controlado (avaliação).

A forte flexibilidade que a globalização admite, estando neste aspecto muito próxima da pós-modernidade, não é mais do que um processo de criação de espaços de responsabilização dos sujeitos, cujas identidades devem estar circunstanciadas a compromissos, a metas a cumprir e a resultados a atingir.

Neste processo de mudança planetária, os indivíduos tendem a ter uma mesma identidade cultural, quer ao nível do consumo de produtos, na exaltação daquilo a que Bourdieu (1998, p.38) chama "o reino absoluto do mercado e do consumidor, substituto comercial do cidadão", quer no plano da educação, isto é, da padronização imposta pela escola.

Esta tendência para a homogeneização e uniformização é alimentada actualmente tanto pelos organismos transnacionais como supranacionais, que impõem agendas em termos de políticas sociais e de políticas educativas centradas na eficiência e qualidade, tentando conjugar o cultural com o económico. Assim, e

...na medida que a combinação entre a expansão econômica e o aperfeiçoamento dos meios de comunicação, [a globalização] favorece uma maior homogeneização dos valores culturais e aponta para a possibilidade de padronização dos indivíduos. Não é à toa que a globalização possibilita que, nas mais diferentes partes do mundo, os indivíduos possam consumir os mesmos produtos e aderir a valores culturais semelhantes. (Gugliano, 2000, p.65) 
Visto que o Estado continua a ter um papel determinante na configuração de políticas educacionais centralistas, ocorre nas escolas um processo de emergência de identidades locais, cuja afirmação depende de um sentido mais amplo de reivindicação, do "regresso aos actores colectivos", na expressão de Bourdieu (200 I ). Para Touraine (1984, p. I4), isto se faz através da história e das organizações num clima de incerteza e na interdependência entre sistema e acção, na medida em que se trata tanto de "um actor social como de um cidadão em que o seu desenvolvimento pessoal é inseparável do progresso social. A liberdade do indivíduo e a sua participação colectiva aparecem indissociáveis".

Todavia, e partindo-se do princípio que não há uma total prescrição, que todas as políticas são imperfeitas e que a prática é sofisticada, complexa e instável, de acordo com o modelo das micropolíticas de Ball (1997), as escolas são estruturas de poder que se constituem em redes informais de decisão de práticas discursivas que intervêm de modo activo nas decisões curriculares. São, portanto, espaços de construção e afirmação de identidades. Reconhecendo que as identidades são socialmente construídas, descentradas, relacionais, fragmentadas, contraditórias e instáveis, Moreira (2006, p.27) interroga-se sobre que "identidades estamos construindo nas escolas e que identidades, na contramão dos padrões hegemónicos, poderíamos construir, transformando nossas práticas curriculares".

O contributo dos Estudos Culturais é significativo para a compreensão desta realidade, cuja leitura da globalização, como processo homogeneizante, alimentada pela ideologia neoliberal, permite identificar a "proliferação subalterna da diferença", isto é, das tendências emergentes que escapam ao hipercontrole, assim caracterizadas por Hall:

Juntamente com as tendências homogeneizantes da globalização, existe a proliferação subalterna da diferença. Trata-se de um paradoxo da globalização contemporânea o fato de que, culturalmente, as coisas pareçam mais ou menos semelhantes entre si (...) Entretanto, concomitantemente, há a proliferação das diferenças. $\bigcirc$ eixo vertical do poder cultural, económico e tecnológico parece estar sempre marcado e compensado por conexões laterais, o que produz uma visão de mundo composta de muitas diferenças locais. (2003, p.60) 
Globalização e identidade...

A emergência destas culturas locais, que na lógica da globalização não passam de disfuncionalidades do sistema, é, aliás, um dos vectores principais dos estudos pós-coloniais" ', sobretudo quando se reconhecem, nos contextos organizacionais formais e/ou informais, espaços para a construção de identidades marcadas por dinâmicas sociais, culturais e ideológicas e por dimensões multiculturais. Por mais unidade que exista em termos de um Estado nacional, o certo é que a sua população é culturalmente heterogénea, crescendo, cada vez mais, "a multiplicidade de formas culturais de vida, grupos étnicos, confissões religiosas e diferentes imagens do mundo" (Habermas, 2002, p.34).

Decorre destas abordagens locais e ligadas a situações específicas a ideia de hibridez, ou seja, a mistura de diversas linguagens que constituem um

...mundo de intersecções e interpretações culturais que remete para uma dimensão epistemológica ao indicar uma certa contextualidade de onde partem as enunciações; uma dimensão heurística, como chave analítica para a compreensão dos processos culturais contemporâneos; uma dimensão política que rompa com os essencialismos padronizadores. (Costa, 2002, p.4)

Aceita-se, assim, que não existe jamais uma globalização totalizante, capaz de abarcar todos os espaços com a mesma intensidade, pois nenhuma cultura se reproduz totalmente; não existe o sujeito racional unificado que se associa ao funcionamento burocrático das escolas (Ladwig, 2003, p.277); e

II. "Pode-se então qualificar a emergência dos Estudos Culturais como a de um paradigma, de um questionamento teórico coerente. Trata-se de considerar a cultura no sentido lato, antropológico, partir de uma reflexão centrada sobre a ligação cultura-nação para uma abordagem da cultura dos grupos sociais. Se permanecer fixa numa dimensão política, a questão central é então a de compreender em que é que a cultura de um grupo, e primeiramente a das classes populares, funciona como construção da ordem social ou, inversamente, como forma de adesão às relações de poder" (Mattelart, Neveu, 2003, p.4). De acordo com Sérgio Costa (2002, p.39), "os estudos pós-colonais não constituem propriamente uma matriz teórica. Trata-se de uma variedade de contribuições com orientações teóricas distintas - algumas mais, outras menos afinadas com a abordagem pós-moderna -, mas que apresentam como característica comum o esforço de esboçarem, pelo método da desconstrução dos essencialismos, uma referência epistemológica crítica vigorosa à modernidade ocidental". 
José Augusto Pacheco e Nancy Pereira

...se, por um lado, a globalização económica atua sobre a esfera cultural com o seu potencial homogeneizador, por outro, mostra-se incapaz de uniformizar a totalidade da cultura. Cria-se, deste modo, uma situação de hibridização cultural tanto nos países centrais como nos periféricos. (Moreira, Macedo, 1999, p.20)

hibridismo, "termo usado para descrever as formas pelas quais determinadas pessoas carregam consigo várias formas de identidade, de subjetividades, se preferirmos, formas essas que são, elas mesmas, definidas em relação a vários conjuntos de relações sociais históricas" (Ladwig, 2003, p.275), dentro de "um processo de tradução cultural" (Hall, 2003, p.74), torna possível contrariar as identidades de legitimação, reconhecendo-se, que há sempre espaço para a construção de identidades pelos sujeitos comprometidos colectivamente com um dado projecto de formação.

Voltando-se à ideia dos espaços e de sua relação com o problema de produção do poder do qual resulta a produção de identidades, Popkewitz afirma que

...as escolas não são unicamente espaços físicos, confinados a uma geografia localizada, que sofrem um processo de normalização, mas também espaços discursivos, constituídos pelo sistema de idéias, distinções e separações que funcionam para confinar o aluno a determinadas normalizações. (200। , p.37)

Com efeito,

... o currículo torna-se a partir deste ponto de vista, parte de um espaço discursivo no qual os sujeitos do ensino (o professor e a criança) são diferenciadamente construídos como indivíduos para se auto-regularem, autodisciplinarem e refletirem sobre si mesmos como membros de uma comunidade/sociedade. (p.38)

A identidade como um outro espaço, que não é totalmente definido e aglutinado pela globalização, remete para questões muito diversas, caso da escolarização comum, da padronização cultural que existe em função de currículos supranacionais ${ }^{12}$ e nacionais, da gestão diversificada do currículo e da definição dos conteúdos trabalhados escolarmente.

12. A este respeito, e tendo como base de trabalho documentos da União Europeia relativos às políticas de educação e formação, registamos o que se pode chamar a emergência do currí- 
Globalização e identidade...

Para que se possa falar de uma "nova lógica política multicultural" é fundamental falar da expansão de práticas democráticas (Hall, 2003, p.89) através do reconhecimento que os actores políticos (especialistas, governantes, professores, alunos, pais, entre outros) têm na configuração dos projectos educativos. Merecem destaque professores e alunos quando se pensa na diversidade como meio de "atender às diferentes necessidades e formas de aprender, às diferentes orientações culturais e às diferentes aspirações a respeito do trabalho e modo de vida, representadas pela diversificada população de alunos das escolas públicas" (Burbules, 2003, p. I61).

Ainda que a autonomia curricular seja limitada, mormente em sistemas centralizados, seja na forma de planos curriculares e programas, seja na forma de objectivos e competências,

...a gestão do currículo (possível graças ao exercício de autonomia relativa por parte do professor) é um projeto importante, potencialmente interessante mas que, simultaneamente, comporta certos riscos (...) ○ simultâneo domínio do conhecimento sobre os alunos e das suas necessidades e interesses, do conhecimento profundo das características do currículo, da consciência construída através da experiência da margem de autonomia que usufrui no espaço da sua profissão, tudo isso abre ao professor a possibilidade de recontextualizar os saberes eleitos como importantes pelo currículo. (Cortesão, Stoer, 2003, p.201-202)

Cria-se a tensão entre a homogeneização cultural, que padroniza os conteúdos de aprendizagem, os métodos de ensinar e as formas de avaliar, originando a retylerização curricular, e a diversidade, que têm marcado profundamente as reformas educacionais das últimas décadas, como se fosse possível conjugar a igualdade de oportunidades culturais com as desigualdades que são produzidas pelas lógicas de escolarização. Pode-se admitir, seguindo-se o pensamento de Popkewitz (200 I , p.2 I), que a escolarização comum dos alunos origina um ensino mais equitativo e justo, mas que os diversos actores educativos têm um fraco entendimento acerca do modo como as práticas es-

culo europeu tanto na forma, sobretudo para o ensino superior, como no conteúdo, nos ensinos fundamental e médio (cf. Pacheco, Vieira, 2006). 
colares actuam para produzir o terreno desigual que é a educação. Para lá dos discursos ideológicos sobre a escola, interroga-se Ladwig (2003, p.265): "O que sabemos a respeito do esforço por tornar as escolas socialmente justas?".

Em resposta, deve-se admitir que as teorias progressivistas falham neste aspecto quando têm como meta buscar a produção de resultados educacionais equitativos, como observa Muller:

Visto que o conhecimento hoje se apresenta, e de maneira tão intensa, bem à nossa frente, como provavelmente sempre ocorreu, não seria o momento de adoptarmos políticas e métodos pedagógicos pós-progressivistas, menos românticos, mais eficazes e mais socialmente justos? (2003, p.3 I 5)

Neste sentido, nem sempre as estratégias curriculares inovadoras são socialmente as mais justas, dado que "podem, paradoxalmente, criar um espaço discursivo no qual se segregam as crianças das camadas populares, reduzindo as suas possibilidades de autonomia na sociedade, frente à criança dos grupos privilegiados" (Moreira, 2006, p. 12).

Diante das desigualdades que existem no terreno das escolas, mais reforçadas ainda com a tendência uniformizante do currículo e dos projectos organizativos, dado que as escolas tendem a ser cada vez mais parecidas entre si, a globalização, se não for admitida como uma inevitabilidade e como algo que institucionaliza uma pedagogia mundial ${ }^{13}$, pode contribuir para a emergência de uma identidade de resistência. Isto porque que os actores educativos são capazes de criar o sentido de pertença a um projecto educacional, onde os conceitos de autonomia, participação, comunidade e projecto não se encontram na discursividade dos normativos e documentos de orientação política da administração central (Pereira, Pacheco, 2005), mas no centro da própria escola. Mais do que alinharmos pelo coro crítico à globalização, denunciando os seus infortúnios, no dizer de Willinsky (2003, p. 103), temos de especificar projectos de intervenção educacional, explorando as potencialidades que existem no interior dos espaços escolares. Para tal, precisamos ainda de reconhe-

13. Uma hipótese de trabalho que pode estar inscrita na agenda de uma pesquisa em torno das políticas económicas e educacionais é a de saber se a uma economia mundial de mercado corresponde um sistema mundial escolar. 
Globalização e identidade...

cer a globalização como política de despolitização, que, para Bourdieu (200 I, p.60), "é efeito não de uma fatalidade económica, mas de uma política consciente e deliberada, mas o mais das vezes inconsciente de suas consequências".

Esta perspectiva de afirmação da identidade escolar é a que está na base dos resultados de investigação que de seguida são analisados.

\section{CURRÍCULO COMO PROJECTO HOMOGÉNEO}

Com os processos de homogeneização existentes dentro de uma orientação para a afirmação de identidades escolares, o currículo continua a ser, no conjunto global das políticas educativas, um dispositivo de formação que é sujeito a reformas constantes. Assim, o currículo como facto (Goodson, 200 I), elaborado e realizado numa perspectiva fechada e de controle administrativo (Doll, 2004), é legitimado ao nível das práticas escolares pela globalização, deixando de ser perspectivado como uma conversação complexa, ou seja, como algo que é construído pelos sujeitos em função das suas identidades (Pinar, 2004).

Assim, no quadro das políticas de descentralização, as escolas como organizações complexas são espaços para a construção de identidades através da elaboração, realização e avaliação de projectos educativos e curriculares. Todavia, a globalização reforça as práticas de uniformização da escola, acentua - lado formal e administrativo do currículo e cria ao mesmo tempo discursos de autonomia, de identidades e de projectos. Como se conjugam estes dois níveis de análise?

Os dados empíricos que apresentaremos, a partir de um estudo qualitativo, tendo como corpus de análise vários projectos da realidade escolar portuguesa, permitem-nos enunciar que as identidades pretendidas são mais discursos políticos de responsabilização das escolas do que documentos de orientação para a planificação das práticas pedagógicas de professores e alunos (Pereira, 2006). Além disso, os dados permitem referir que os projectos educativos e curriculares são sobretudo projectos homogéneos, elaborados em função de orientações normativas e comuns a todas as escolas.

Mais do que o reconhecimento das identidades de projecto e de identidades profissionais, se seguirmos a tipologia de Castells (2000a), a globalização arrasta consigo uma identidade legitimadora, que, enquanto fenómeno 
cultural ${ }^{14}$, é introduzida pelas instituições dominantes da sociedade no intuito de expandir e racionalizar a sua dominação em relação aos actores sociais.

A regulação supranacional das políticas educativas ao nível da União Europeia (a Declaração de Bolonha, para o ensino superior, é um bom exemplo) é uma forma de legitimação de processos e práticas de decisão propostos em torno de uma identidade homogénea, uniformizadora e convergente.

Neste caso, a europeização do currículo, que se estende a todos os níveis de ensino, embora mais na forma para o ensino superior e mais no conteúdo para os ensinos fundamental e médio, está baseada na centralidade do conhecimento e na adopção de políticas sociais mais eficientes, com destaque para o controle dos sistemas de educação e formação.

Tal processo de globalização regional impõe uma identidade legitimadora através de referenciais ligados à definição de competências-chave (sobretudo nas áreas das Tecnologias de Informação e Comunicação e das Letras), ao estabelecimento temporal de resultados esperados de aprendizagem e à formatação e organização dos ciclos de formação (Pacheco, Vieira, 2006).

Quando inscrita numa agenda de performatividade e gestão escolar e de estandardização curricular, a identidade legitimadora origina ao nível do contexto de trabalho dos professores a identidade empresarial que Sachs associa a

...professores eficientes, responsáveis e responsabilizáveis, que demonstram submissão aos imperativos políticos impostos externamente e que possuem um ensino de elevada qualidade, avaliado com base num conjunto externo de indicadores de competência. Esta identidade poderá caracterizar-se como sendo individualista, competitiva, controladora e reguladora, definida externamente e orientada para standards. (apud Day, 2006, p.89)

Mas, de que modo os professores podem reagir a estas identidades legitimadora e empresarial que lhes impõem práticas idênticas trazidas pela homogeneização?

14. A globalização favorece a padronização da cultura mundial, assim analisada por Nogueira (200 I , p. I38), a partir do princípio que a economia torna-se numa questão cultural: "A produção de bens de consumo é agora um fenômeno cultural: compra-se o produto tanto por sua imagem quanto pela sua utilidade imediata". 
Globalização e identidade...

Sachs (2003) propõe a identidade activista, ou seja, a acção comprometida com a melhoria das condições de aprendizagem dos alunos e que se afasta tanto do ensino individualista e isolado quanto das propostas de instrumentalismo técnico existentes ao nível das reformas educativas e curriculares.

A colaboração entre professores, e entre estes e os demais actores educativos, é condição indispensável para a construção de uma identidade de resistência ou de projecto, definidas por Castells (2000a) como produzindo, respectivamente, a visibilidade dos actores que se encontram em posições/ condições desvalorizadas e/ou estigmatizadas pelas lógicas de dominação e a afirmação dos actores que são capazes de redefinir a sua posição na sociedade.

Visto que toda a identidade é construída histórica e socialmente, a formação de identidades ligadas a contextos profissionais como o do ensino, seguindo-se a argumentação de Day (2006), é algo mais marcado pelas questões técnicas (gestão da sala de aula, conhecimento da disciplina, resultados dos testes dos alunos) do que pelas questões de natureza pessoal, profissional, social e emocional. Os contextos de ensino são essencialmente produtores de identidades técnicas, pois os professores, no contexto das políticas de homogeneização da educação, são mais avaliados e responsabilizados pelo lado dos resultados dos alunos do que pelo seu lado mais pessoal e de gestão dos processos de aprendizagem.

A ideia de resistência dos professores é essencialmente marcada não pela construção de alternativas ou pela afirmação de uma cultura de contestação, mas pela adopção de uma estratégia de sobrevivência que inclui o que Lacey (1977, p. 72) denomina por submissão estratégica. Ou seja, "o sujeito concorda com a definição da figura de autoridade e com os constrangimentos da situação, mantendo as suas reservas". Tal estratégia é visível no distanciamento que os professores têm relativamente às reformas curriculares (Pacheco et al., 1996) e no modo como reconfiguram as suas práticas curriculares.

Num estudo empírico realizado por Pereira (2006), os projectos educativos, e poder-se-á o mesmo dizer dos projectos curriculares de escola e de turma, não cumprem, na prática, as orientações que estão na base da sua elaboração, pois os professores aceitam-nos como documentos de ritualização escolar.

Com efeito, os projectos de escola, ao contrário do que seria de esperar, não são o resultado da acção dos diferentes actores educativos, principal- 
mente de professores e alunos, apresentando-se como o somatório de políticas educativas concretas, com uma identidade normativa bem vincada. Tal situação prende-se quer com um excesso de regulamentação, quer com a existência de inúmeras incongruências entre o plano da regulação normativa e da acção, dado que a lógica dominante é a do controle hierárquico e da produção de normativos, enquanto uma política de reforço da autonomia implica uma lógica de funcionamento centrada na prestação de serviços de apoio.

No mesmo estudo (Pereira, 2006), constata-se que, em Portugal, os docentes ainda se encontram numa situação de resistência perante medidas que visam melhorar a qualidade do serviço prestado pelas escolas assente numa maior autonomia destas. Esta concepção redutora da actividade docente constitui-se como um dos maiores inimigos da implementação da autonomia das escolas no sentido em que esta exige abertura, cooperação, inovação, participação em órgãos colectivos e actividades de equipa por parte de docentes ou de outros parceiros. Segundo Nóvoa, citado por Teodoro (1994, p.23), para inverter este estado é preciso convencer os docentes de que devem assumir uma postura diferente, abandonando "o comportamento defensivo, mais próprio de funcionários do que de verdadeiros profissionais". Esta visão deve ser encarada como uma mentalidade que é necessário fazer evoluir, demonstrando exemplarmente os benefícios de uma autonomia assumida, com formação contínua adequada e com estímulos relacionados, por exemplo, com a progressão na carreira. Consideramos também que esta evolução é um desafio necessário que se coloca aos docentes, às escolas e ao poder político, na medida em que o "isolacionismo" docente refugia-se em posições corporativistas que visam a defesa do controle da escola por parte dos docentes.

Num outro estudo, Roldão sublinha a sobrecarga burocrática real e a escassa eficácia que esses documentos originam,

...visto apenas como textos escritos, a produzir uma lógica de conformidade, difíceis de articular entre si, na perspectiva dos professores, e de uma utilidade que se lhe apresenta, no quadro da cultura de escola e da profissão em que estão inseridos, no mínimo duvidosa. (2005, p.69)

O lado da burocracia escolar é um dos parâmetros essenciais para a adopção de uma estratégia de sobrevivência por parte dos docentes, na me- 
Globalização e identidade...

dida em que as suas práticas não se alteram a partir de normativos, mantendo-se enquadradas numa tradição alicerçada em práticas uniformes. Neste sentido, na avaliação dos projectos de escola,

...parece assim evidenciar-se um carácter retórico dos documentos que não provêm apenas da visão um pouco "seguidista" dos docentes, aliás historicamente explicável, mas também dos efeitos dessa mesma história e seus mecanismos instituintes ao nível de todo o sistema e dos diversos agentes da sua administração, todos eles portadores, tal como os docentes, de culturas burocráticas fortemente enraizadas que, justamente, não podem mudar-se por via igualmente burocrática. (Roldão, 2005, p.67).

Tratando-se da construção de um identidade de resistência passiva, os professores perante as exigências administrativas tornam-se eles próprios normativistas. No estudo de Roldão, para o ensino básico em Portugal, "constatouse, assim, mais uma vez, no clima e na cultura dos professores, da escola e do sistema, um conjunto de contradições evidentes que leva os professores a desenvolverem uma postura cada vez mais orientada para a normatividade" (p.59).

No estudo de Costa, Dias e Ventura (2005), no contexto da reorganização curricular, o comportamento dos professores "parece ter sido mais reactivo, mais orientado pela necessidade de cumprir o melhor possível o que os normativos legais determinam" (p. | |7).

A identidade de projecto, sinónimo de uma proposta de alteração das práticas instituídas, é, assim, algo que existe dentro de uma identidade de legitimação e que procura através de normativos impor a mudança e inovação sem que as práticas sejam modificadas nos seus aspectos mais substantivos. À luz de resultados de estudos empíricos realizados em Portugal (Pacheco, 2002), verifica-se que os conceitos de autonomia, participação, comunidade, projecto e descentralização, entre outros, se encontram preferencialmente na discursividade dos normativos e documentos de orientação política da administração central, e não nas práticas dos professores.

\section{NOTAS FINAIS}

Em tempos de globalização, a regulação da educação é cada vez mais realizada em contextos supranacionais, impondo-se, por um lado, um padrão 
comum de pensar a formação dos alunos e de organizar o currículo e, por outro, práticas curriculares homogéneas e orientadas pela eficiência dos resultados de aprendizagem. A identidade e a autonomia curriculares da escola são aspectos valorizados nos discursos políticos, mas facilmente contraditados pelas práticas escolares. Na resenha de estudos realizados em Portugal, concluise: a europeização do currículo está ligada à imposição de competências-chave e à uniformização dos ciclos de formação, favorecendo a identidade empresarial; os professores se enquadram numa lógica de cumprimento das normas da administração, elaborando os projectos, que potencialmente lhes trariam autonomia e identidade, na forma de ritualização de procedimentos.

Neste sentido, os projectos elaborados ao nível da escola são documentos que contribuem para o reforço do currículo nacional e supranacional. Podemos, assim, argumentar que a globalização não só reduz o espaço escolar de construção de identidades curriculares, bem como tende para a legitimação de práticas escolares uniformes, tornando o currículo num facto, num episódio conducente à eficiência dos resultados de aprendizagem dos alunos, desvalorizando aspectos que são fundamentais na sua formação global.

\section{REFERÊNCIAS BIBLIOGRÁFICAS}

ARRIGHI, G.; SILVER, B. (org.) Caos e governabilidade no moderno sistema mundial. Rio de Janeiro: Contraponto, Editora UFRJ, 2001.

BALL, S. The Micro-politics of the school. London: Methuen, 1997.

BERNSTEIN, B. A Estruturação do discurso pedagógico: classe, códigos e controle. Petrópolis: Vozes, 1996.

BORTONI-RICARDO, S. Nós cheguemu na escola, e agora? São Paulo: Parábola, 2005.

BOURDIEU, P. Contrafogos 2: para um movimento social europeu. Oeiras: Celta, 2001. Questions de sociologie. Paris: Les Éditions de Minuit, 1998.

BURBULES, N. Uma gramática da diferença: algumas formas de repensar a diferença e a diversidade como tópicos educacionais. In: GARCIA; R. L.; MOREIRA, A. F. (org.) Currículo na contemporaneidade: incertezas e desafios. São Paulo: Cortez, 2003. p. I59-I88.

CASTELLS, M. Fim de milênio. São Paulo: Paz e Terra, 2000. (Coleção A era da informação: economia, sociedade e cultura, 3) 
Globalização e identidade...

. O Poder e a identidade. São Paulo: Paz e Terra, 2000a. (Coleção A era da informação: economia, sociedade e cultura, 2)

A Sociedade em rede. São Paulo: Paz e Terra, 2000b. (Coleção A era da informação: economia, sociedade e cultura, I)

CORTESÃO, L.; STOER, S. A Interface de educação intercultural e a gestão de diversidade na sala de aula. In: GARCIA; R. L.; MOREIRA, A. F. (orgs.) Currículo na contemporaneidade: incertezas e desafios. São Paulo: Cortez, 2003. p. 189-208.

COSTA, S. Teoria social, cosmopolitismo e as sociedades pós-nacionais. In: SCHERERWARREN, I.; FERREIRA, F. (orgs.) Transformações sociais e dilemas da globalização: um diálogo Brasil/Portugal. São Paulo: Cortez, 2002. p.23-46.

COSTA, J. A.; DIAS, C.; VENTURA, A. Reorganização curricular do ensino básico: projecto, decreto e práticas nas escolas. Aveiro: Universidade de Aveiro, 2005.

DAY, C. A Paixão pelo ensino. Porto: Porto Editora, 2006.

DOOL, W. Currículo e controlo. Revista de Estudos Curriculares, v.2, n. I, p.7-42, 2004.

FERREIRA, N. (org.) A Gestão da educação na sociedade mundializada. Rio de Janeiro: DP\&A, 2003.

FREIRE, P. Pedagogia da autonomia: saberes necessários à prática docente. São Paulo: Paz e Terra, 1996.

GARCIA, R. L.; MOREIRA, A. F. Começando uma conversa sobre currículo. In: GARCIA; R. L.; MOREIRA, A. F. (orgs.) Currículo na contemporaneidade: incertezas e desafios. São Paulo: Cortez, 2003. p.7-40.

GIDDENS, A. O Mundo na era da globalização. Lisboa: Presença, 2000.

GIMENO, J. O Significado e a função da educação na sociedade e na cultura globalizadas. In: GARCIA, R. L.; MOREIRA, A. F. (orgs.) Currículo na contemporaneidade: incertezas e desafios. São Paulo: Cortez, 2003. p. 4|-80.

GOODSON, I. Currículo em mudança. Porto: Porto Editora, 2001.

GOUGH, N. Globalization and school curriculum change. In: DAVID, S. (ed.) Curriculum studies, 4. London: Routledge, 2003. p. 1 48- 162.

GUGLIANO, A. Nas costas da globalização: as perspectivas dos países periféricos frente às transformações da economia internacional. In: FERREIRA, M.; GUGLIANO, A. (orgs.) Fragmentos da globalização na educação. Porto Alegre: Artmed, 2000. p.63-76. 
HABERMAS, J. A Inclusão do outro: estudos de teoria política. São Paulo: Loyola, 2002.

HALL, S. Da diáspora: identidades e mediações culturais. Belo Horizonte: Editora UFMG, 2003.

HALLAK, J. Politiques éducatives et contenus d'enseignement dans les pays en développement. In: CARPENTIER, C. (coord.) Contenus d'enseignement dans un monde en mutation. Paris: L'Harmattan, 200 I. p.3I-52.

HARGREAVES, A. O Ensino na era do conhecimento. Porto: Porto Editora, 2004.

JAMESON, F. Globalização e estratégia política. In: SADER, E. (org). Contracorrente. Rio de Janeiro: Record, 200I, p. $133-158$.

KOVÁCS, I. Qualificações e ensino/formação na era da globalização. In: ARRIGHI, G.; BEVERL, S. Caos e governabilidade no moderno sistema mundial. Rio de Janeiro: Contraponto, Editora UFRJ, 2002. p. $147-166$.

KRESS, G. O Ensino na era da informação: entre a instabilidade e a integração. In: GARCIA, R. L.; MOREIRA, A. F. (orgs.) Currículo na contemporaneidade: incertezas e desafios. São Paulo: Cortez, 2003. p. I |4-138.

LACEY, C. The Socialization of teachers. London: Methuen, 1977.

LADWIG, J. Primeiras aproximações a uma pedagogia mundial. In: GARCIA, R. L.; MOREIRA, A. F. (orgs.) Currículo na contemporaneidade: incertezas e desafios. São Paulo: Cortez, 2003. p.265-292.

MARTINAND, J. L. Matrices disciplinares et matrices curriculares: les cas de l'éducation technologique en France. In: CARPENTIER, C. (ed.) Contenus d'enseignement dans un monde en mutation. Paris: L'Harmattan, 200 I. p.249-269.

MATTELART, A.; NEVEU, É. Introduction aux cultural studies. Paris: La Découverte, 2003.

MORAES, M. C. O Renovado conservadorismo da agenda pós-moderna. Cadernos de Pesquisa, v.34, n. I22, p.337-357, maio/ago.2004.

.Por que ter medo dos conteúdos? In: PEREIRA, M. Z.; MOURA, A. P. (orgs.) Políticas e práticas curriculares: impasses, tendências e perspectivas. João Pessoa: Idéia, 2005. p. I I-42.

MOREIRA, A. F. Desafios contemporâneos no campo da educação: a questão das identidades. In: MOREIRA, A. F.; PACHECO, J. A. (orgs.) Globalização e educação: desafios para as políticas e práticas. Porto: Porto Editora, 2006. p. 1 I-29.

MOREIRA, A. F; MACEDO, E. Faz sentido ainda o conceito de transferência educacional? In: MOREIRA, A. F. (orgs.) Currículo: políticas e práticas. Campinas: Papirus, 1999. p. I I-30. 
Globalização e identidade...

MORIN, E. Os Sete saberes necessários à educação do futuro. São Paulo: Cortez, Unesco, 2001 .

MULLER, J. Revisitando o progressivismo: ethos, política, pathos. In: GARCIA, R. L.;. MOREIRA, A. F. (orgs.) Currículo na contemporaneidade: incertezas e desafios. São Paulo: Cortez, 2003. p.293-318.

NOGUeIRA, M. Em defesa da política. São Paulo: Senac, 2001.

NÓVOA, A. Currículo e docência: a pessoa, a partilha, a prudência. In: GONSALVES, E.; PEREIRA, M. Z.; CARVALHO, M. E. (orgs.) Currículo e contemporaneidade: questões emergentes. Campinas: Alínea, 2004. p. 17-29.

PACHECO, J. A. Descentralizar o discurso das competências. Revista de Estudos Curriculares, v.3, n. I, p.65-91, 2005.

Em torno de um projeto curricular pós-colonial. In: MOREIRA, A. F.; PACHECO, J. A.; GARCIA, R. L. (orgs.) Currículo: pensar, sentir e diferir. Rio de Janeiro: DP\& A, 2004. p.43-50.

. Estudos curriculares: para uma compreensão crítica da educação. Porto: Porto Editora, 2005a.

- Notas para uma síntese de uma década de consolidação dos estudos curriculares. Investigar em Educação, v. I, n. I, p.227-273, 2002.

O pensamento e a ação do professor. Porto: Porto Editora, 1995

PACHECO, J. A. (org.). O Neoliberalismo em educação. Porto: Porto Editora, 2001.

PACHECO, J. A.; VIEIRA, A. P. Europeização do currículo: para uma análise das políticas educativas e curriculares. In: MOREIRA, A. F.; PACHECO, J. A. (orgs.) Globalização e educação: desafios para as políticas e práticas. Porto: Porto Editora, 2006. p.87-I26.

PACHECO, J. A. et al. O Impacto da reforma curricular no pensamento e na acção do professor. relatório de investigação. Braga: Universidade do Minho, 1996.

PEREIRA, N. Projecto educativo de escola: um desafio à organização escolar. Dissert. (mest.) Universidade Portucalense: Porto, 2006.

PEREIRA, N.; PACHECO, J. A. Projecto educativo: um estudo sobre as representações de professores do ${ }^{\circ}$ ciclo do ensino básico. In: SILVA, B.; ALMEIDA, L. (orgs.) Actas do VIII Congresso Galaico-Português de Psicopedagogia. Braga: CIEd, 2005. p.3.323-3.333.

PINAR, W. What is curriculum theory? New York: Peter Lang, 2004. 
POPKEWITZ, T. Lutando em defesa da alma: a política do ensino e a construção do professor. Porto Alegre: Artmed, 2001.

ROLDÃO, M. C. (coord.) Formação e práticas de gestão curricular. crenças e equívocos. Porto: Asa, 2005.

SACHS, J. The Activist teaching profession. Buckingham: Open University Press, 2003.

SAMPAIO, M. Um gosto amargo de escola. São Paulo: Educ, 1998.

SANTOS, B. Processos de globalização. In: SANTOS, B. S. (org.) A Sociedade portuguesa perante os desafios da globalização: modernização económica, social e cultural. Porto: Afrontamento, 2001. p.31-106.

TEIXEIRA, E. O Local e o g/obal: limites e desafios da participação cidadã. São Paulo: Cortez, 2001.

TEODORO, A. Globalização e educação. Porto: Afrontamento, 2003.

Política educativa em Portugal: educação, desenvolvimento e participação política dos professores. Lisboa: Bertrand Editora, 1994.

TOURAINE, A. Le Retour de l'acteur. essai sur sociologie. Paris: Fayard, 1984.

WILLINSKY, J. O Estado-Nação após o globalismo. In: GARCIA, R. L.; MOREIRA, A. F. (orgs.) Currículo na contemporaneidade: incertezas e desafios. São Paulo: Cortez, 2003. p.8I- $\mid 14$.

Recebido em: maio 2006

Aprovado para publicação em: novembro 2006 